\title{
An Analysis on the Causes of the Destruction of Western Roman Empire Zhiyong Chang
}

\author{
School of History and Culture, Hebei Normal University, Shijiazhuang, 050024, China
}

Keywords: Western Roman Empire; causes of the destruction; pestilence; plumbism; class contradictions

\begin{abstract}
Researchers have always held various opinions towards the causes of the destruction of Western Roman Empire, each of their opinions possessing its own advantage. Thus, there isn't an opinion which can obtain acceptance of all people. Conbining with predecessors' research viewpoints, this eassy has an analysis on the causes of the destruction of Western Roman Empire from the aspects such as prevailing of pestilence, plumbism, intensifying of class contradictions.
\end{abstract}

\section{Introduction}

Roman Empire was once an illustrious empire in the world history. Its capital Roman was praised as "Eternal City". The glorious Roman culture created by ancient Romans is respected by later generations all the time. The period between the first and the second century A.D. is the golden age of Roman Empire. Thereafter, the empire is divided into the western and the eastern parts. Western Roman Empire completely destruction in 476 A.D., which is of great influence on the development of Europe and even the whole world. The causes of the destruction of Western Roman Empire has always been the focus issue for historical researchs. Although researchers from different eras have different emphasis on searching the causes, most of them believe that the causes can not be so simple but contain the influence of various factors. The author hope to investigate thoroughly the causes of the destruction of Western Roman Empire from the following three factors.

\section{Prevailing of Pestilence}

Roman Empire has gradually become a giant empire with prosperous dometic commerce and convenient transportation stretching across Europe, Asia, and Africa after long-time development. In terms of climate, most of its land lie in the climatic regions of Mediterranean and tropical desert climate. Infectious diseases can spread easilier and more quickly in these climatic regions than other regions. Pestilence refers to infectious fever caused by yersinia pestis carried by fleas on the body of mouse. People will go down with the disease after touching infectious fleas on the body of mouse. In some cities with relatively dense population, pestilence is transmitted to people from mouse and then is likely spreading all over the city. The break out of pestilence possesses the characteristics of burstiness, universality and rapidness so that it is hard to avoid to be infected. Especially under the condition that information and technology are relatively not so advanced in ancient times and people are in shortage of enough warning consciousness and precautionary measures and with the limitation of medical conditions, people are helpless when confronted with the prevailing of pestilence. Lying in the Mediterranean coast, the location of Roman Empire contributes to the prevailing and spreading of pestilence.

Although pestilence is not primary cause and immediate cause of the destruction of Western Roman Empire, it has caused huge disaster and loss to the empire because of its periodic and continued breakout. And the huge disaster and loss are fully reflected in the declining of Roman city. The commerce of ancient Rome is prosperous, the population mobility is strong and the transportation is convenient. At that time, there are big cities such as Rome and Alexander. The damage to cities caused by pestilence is further more severe than that to villages and the death rate of cities is surelly for surpassing that of villages. This is because the population density of cities is highly above that of villages and the necessities of life such as food can not be self-sufficient for cities and the contact range is relatively wider. Since the pestilence breaks out on a large scale of 
cities, due to the mass mortality, food producers and carriers are decreasing and those people who luckiy escape from pestilence starve to death because of severe food shortage. At the same time, some people get infected again because they can not get enough food and then their body resistence are continually declining. According to the historical records, whenever pestilence is prevailing, famine will soon break out and quickly spreading all over the regions. Famine cause the rapid decline of body resistence, which adds to the damage caused by pestilence. Although the treatment towards diseases is becoming more and more reasonable and many medical facilities are founded in large and medium-sized cities, pestilence still brings about injuries and deaths of a large number of citizens because of pestilence's power is incredibly huge and the pathogenesis can not be accurately found within a short period. Pestilence kills numbers of people, which brings about the sharply decline of fiscal revenue and the failure of cities' management systems. All these gradually lead to the declining of the empire.

In the aspect of army, pestilence decreases the number of troops and injures soldiers' bodies, causing the declining of fighting capacity of army, which is a dody blow to Roman Empire which founds the country through military expansion. The significant reduction of the number of soldiers will surely bring about the weaken of fightin capacity of army and thus put the empire always at a disadvantage in its late military fighting. The serious casualties caused by pestilence directly brings about the sharp decrease of the sources of troops and gradually it leads to the phenomenon of insufficient army, inadvanced weapons, and lack of poweful fighting capacity in the late period of Roman Empire. As a result, different races such as Germanic people and Goths frequently invade Roman Empire. Facing the danger of alien attack, Western Roman Empire has to call up a great number of lansquenet from barbaric ethnic groups. This makes Roman army begins to be barbarized step by step, which directly leads to many occurrences of discord in the late period of the empire and meanwhile indirectly leads to turbulence of Western Roman Empire's political situation. This adverse effect to Western Roman Empire caused by this phenomenon runs through the destruction history of the empire. After the prevailing of pestilence, the war situation change from attack to defend gradually and successive rulers all choose to sign a peace treaty allowing the freedom of residence for barbaric ethnic groups for the sake of mantaining their government. All the above things prove that pestilence sharply decreases the population of the Western Roman Empire and thus reduces its military power. Because Western Roman Empire is beaten again and again in foreign wars, the territory is shrinking continually. What's worse, it gives an opportunity to invade Roman territory. Finally, the empire fails to maintain its government and soon destructions.

\section{Plumbism}

In the late $60 \mathrm{~s}$ of $20^{\text {th }}$ century, a team of archaeologists excavated a complex of Roman tombs which belongs to the period between the 4th century and the 5th century. Archaeological workers found more that 400 skeletons from the tombs and surprisingly found that lead tolerence for most skeletons is 80 times that of normal people, especially for chilren's skeletons. These people may died from plumbism. In the 80s, researchers published an article in Times showing that the reason why Western Roman Empire was gradually declining because of plumbism is that the feed piping in Rome city is made of lead. As time goes by, lead is gradually corroded and Roman citizens' intelligence is fading because of long-time using of lead pipes. In the 5th century A.D., Western Roman Empire's production and application of lead reachs its peak. dominance hierarchy is proud of using lead products in different occasions. Roman advanced metallurgy and great favor of lead lay a solid fundation for Western Roman Empire's destruction. Lead is widely applied in engineering construction, military and ordinary ornaments. Lead also appears in many aspects of lives of nobility. For instance, lead is used to produce toys, coins, cosmetics and drugs. And lead material also shows its usage in tableware, kitchen ware, and vessels. Meanwhile, lead is applied in water supply system which is exactly what Roman are proud of. According to documentary records, Rome city has 11 main water supply channels, leading to everywhere of the city. Sparge pipes distribute among streets and alleys, providing daily water used in drinking, washing and bathing with citizens. Among these water pipes, there are many that are made of lead due to the good 
sealing property of lead water pipes. Although it costs much to produce lead pipes, almost all officers and nobility choose to use lead water pipes because of the outstanding performance. They not only use the lead pipes to deliver water but also use lead cups to drink water and use lead pot to cook meals and even use lead oxide instead of sugar to mix wine. All these gradually make the civilized life of Roman citizens hang over the huge shadow of plumbism. People will be week all over after long-term contacting and using of lead products. Pleigne, a write in ancient Rome has mentioned in his work that some people ceaselessly shake their hands and become paralytic after drinking wine using cups that are made of lead material. To explain with the help of modern medicine, it is very likely the symptom of mental numbness caused by plumbism. If things continue this way, the lead accumulated in human bodies will start to release its huge power. Records say that the average lifetime of Roman nobility is only 25 years old. Another bad consenquence of eating a great deal of lead is the loss of potentia generandi. Modern medicine has proved that even inhaling tiny lead has a bad impact on reproductive capacity. For instance, amony Troy nobility in ancient Rome, over half of married nobility who are about 35 years old have the problem of sterility. Although other nobility are able to give birth to babies, most of the babies born are subnormal and oafish. Thus, the quality of dominance hierarchy of Western Roman Empire is on the decline so that it is inevasible for the whole empire moving towards destruction.

\section{Intensifying of Class Contradictions}

Slavery system is full of bloodiness and violence since it comes into being. As a result, in view of the development of culture and society, it will surely comes to an end and be replaced by new social system which is more civilized and advanced. The development of Western Roman Empire under the rule of slavery system is without exception. Because of the sharply decline of slaves, continuous recession of economy, and draining of finance, slaveholders strengthen the exploitation to the salves, which leads to the intensifying of class contradictions. The change of forms of exploitation brings about appearance of the productive relations of feudal system. Thereafter, because the these problems is becoming more and more serious and hard to be solved fundamentally, Western Roman Empire finally destructiond in 476 A.D. Specifically, the class contradictions are mainly reflected on the following aspects.

First of all, slaveholders always reply on slaves' labour. Roman nobility's degree of dependence on slaves brings about severe consequence. On the one hand, Roman nobility look down upon ordinary workers and they are extravagant and corrupted without any sense of frugalness. On the other hand, due to the fallen economy and finance, Roman nobility have to increase exploiting grassroots in order to maintain their extravagant life.

Furthermore, slaveholders are afraid of revolt and rebell launched by slaves due to the inhuman treatment, so they adopt kinds of meausures to impose restrictions on slaves' personal liberty. For an example, slaveholders prefer to let slaves wear heavy fetters when working rather than get rid of the fetters so as to improve the work efficiency. Slaveholders even wear a iron collar on the neck of each slave. Those slaves who escape or fail in revolt will get miserable punishment, the ones who escape being branded on forehead and the ones who fail in revolt being nailed on cross and tortured to death. All these brutal acts is of bad influence on the empire's development of productive forces. At the same time, the most miserable thing is that the prevailing of wrestle. Wrestle slaves have to learn the skill of bayonet charge under the condition of being lashed and clubed and they are naked and frequently sent to abattoirs to fight with other slaves or beasts, to kill opposite side or be killed. Wrestle severely destroy the slave labor. These exploitation and oppression makes the class contradictions more and more serious. Sabotage, escape and revolt are of frequent occurrence. All kinds of revolts and campaigns take place under the condition of exploitation and oppression without exception, which acts a strong strike on ruling order of Western Roman Empire's nobility. In result, Western Roman Empire is swaying in the midst of raging storm.

Last but not least, fighting capacity of Roman army is greatly declined. The army of Western Roman Empire adopts citizen soldier system and is mainly made up of free men, who gradually becomes the powerful backbone of slaveholders and the empire. As a result, the power mostly 
depends on the number of free men. However, The long-term large-scale salves' production extrudes the work of free men so that a lot of free men become lumpen-proletariats and homeless, or even become slaves and colonus. In this way, the manpower resources of Western Roman Empire is always not enough, which is a huge threat to the peace of the empire. The rulers of Western Roman Empire have to recruit large quantities of slaves and even criminals to increase the manpower resources. Thereafter, the rulers even get barbaric ethnic groups included so as to supply the sources of troops. Thus, Western Roman Empire which becomes stronger and stronger through military incursion do worse and worse in maintaining its public security, consolidating its politic power and resisting foreign invasion in its vast territory. Due to the long-standing cruel exploitation in Western Roman Empire, the slaves, peasant and colonus prefer to be oppressed by other ethnic groups rather than suffer from slavery of slaveholders and nobility. Therefore, being plagued by all kinds of crisis, Western Roman Empire naturally can not keep going any more. In short, the decline and destruction of Western Roman Empire is closely related to the irreconcilable class contradictions and dissimilation of class relations. One cause of the fall of Western Roman Empire is the intensifying of class contradictions due to the fading of slavery system.

\section{References}

[1]Zhang Qizheng. A Talk about the Causes of the Destruction of the Western Roman Empire A Concurrent Comparison with the Han Empire [J]. Journal of Hunan University of Technology (Social Science Edition), 2001 (4).

[2]Wang Yanqing. The Plague and the Decline of Western Roman Empire [J]. Qilu Journal, 2005 (6).

[3]Lu Xia. Extreme Inflation of Individual Consumption and the Decline of the Western Roma Empire [J]. Journal of Shaoyang University (Social Science Edition), 2007 (1).

[4]Liu Linhai. Historians' comments on Researchs on the Poblems of the Western Roman Empire's Decline [J]. Journal of Historiography, 2010 (4). 